\title{
Erratum to: The researcher and the consultant: a dialogue on null hypothesis significance testing
}

\author{
Andreas Stang $\cdot$ Charles Poole
}

Published online: 13 March 2014

(C) Springer Science+Business Media Dordrecht 2014

\section{Erratum to: Eur J Epidemiol (2013) 28:939-944 \\ DOI 10.1007/s10654-013-9861-4}

In the original publication of the article there are some errors. Please see below the corrections.

Page 3, second column, ninth full paragraph:

"[A] little greater than $3 \%$ " should read, "a little greater than $3 \%(0.033) . "$
The online version of the original article can be found under doi:10. 1007/s10654-013-9861-4.

\section{A. Stang ( $\square)$}

Medical Faculty, Institute of Clinical Epidemiology, MartinLuther-University of Halle-Wittenberg, Magdeburger Str. 8, 06097 Halle, Germany

e-mail: andreas.stang@medizin.uni-halle.de

\footnotetext{
A. Stang

Department of Epidemiology, School of Public Health, Boston University, 715 Albany Street, Talbot Building, Boston,

MA 02118, USA

C. Poole

Department of Epidemiology, Gillings School of Global Public Health, University of North Carolina, Chapel Hill,

NC 27599-7435, USA

e-mail: cpoole@unc.edu
}

"[A] little less than $3 \%$ " should read, "a little greater than $3 \%(0.033)$ as well."

"[A] two-sided $p$ value of about $6 \%$ " should read, "a two-sided $p$ value of about $7 \%$ (0.066)."

Acknowledgments The authors thank Etsuji Suzuki of Okayama University, Okayama, Japan for bringing these errors to their attention. 